\title{
Reinforcement and curing characteristics of organoclay filled natural rubber nanocomposites
}

\author{
G M C Alwis*, U N Ratnayake** and N Kottegoda***** \\ * Department of Chemistry, University of Sri Jayewardenepura, Nugegoda, Sri Lanka \\ ** Rubber Research Institute of Sri Lanka, Telawala Road, Ratmalana, Sri Lanka \\ *** Sri Lanka Institute of Nanotechnology, Mahenwatta, Pitipana, Homagama, Sri Lanka
}

Received: 29 May 2014

\begin{abstract}
Natural rubber (NR) - organoclay nanocomposites (NROCN) and NR-clay (unmodified montmorillonite clay) composites (NRCC) were prepared using different loading of OC/unmodified clay by melt compounding process using a laboratory scale internal mixer in view of investigating the organoclay $(O C)$ effect on curing characteristics and reinforcing behaviour in NR compound formulations.

$X$-ray diffraction analysis of NROCN's revealed predominantly exfoliated $O C$ structures within the NR nanocomposite materials, especially with a lower loading of OC where as NRCC's showed MMT clay aggregates with larger clay stacks leading to conventional NR composite materials.

Vulcanization characteristics of the clay filled NR compounds, especially processing safety, curing time and delta torque, have been interpreted with respect to the organic modifier in the OC and OC clay loading.

NROCN vulcanizates have shown a significant enhancement in solid-state mechanical properties compared to those of NR gum and NRCC vulcanizates. Mechanical property data have been explained in terms of compatibility, degree of exfoliation and clay loading.
\end{abstract}

Key words: exfoliation, nanocomposite, natural rubber, montmorillonite, organoclay, reinforcement, vulcanization

\section{Introduction}

Natural rubber can be converted into useful elastomeric engineering materials for many applications when it is reinforced with filler material. In general, filler can be defined as fine particulate materials that are often used to enhance the performances and various functional properties of the elastomeric matrix, depending on the applications. The main aim of filler addition is to improve physio- 
mechanical properties and to reduce the cost of the compound. Typical reinforcing filler used in rubber compounding is carbon black and silica and, use of carbon black with rubber causes environmental pollution and gives a rubber a black colour (Galimberti, 2011). However, for lighter coloured rubber products, silica filler is commonly used (Chonkaew et al., 2011; Murakami et al., 2001; Poh and Ng, 1998).

In recent past, polymer nanocomposites have attracted a great interest in both academia and industry as an alternative for conventional polymer composites because of the unique properties achieved with the nanocomposites (Ratnayake and Haworth, 2006; Ratnayake et al., 2008). Furthermore, in recent years rubber-clay (layered silicate) nanocomposites have shown a great potential over conventional carbon black filled rubber compounds, because they often exhibit remarkable improvement in material properties when compared with neat rubber or conventional rubber compounds (Zhang et al., 2008). Among natural clays, montmorillonite (MMT) clay is the most commonly used reinforcing material in nanocomposite preparation due to its high cation exchange capacities, large surface area, good surface reactivity and surface adsorptive properties. In general, clay minerals are composed of silicate layers/platelets of $1 \mathrm{~nm}$ thick and 200-300 $\mathrm{nm}$ in the lateral dimensions. Depending on the strength of interfacial interactions between the polymer matrix and the silicate layers, conventional, intercalated and exfoliated nano composites are thermodynamically achievable (Qureshi et al., 2010; Zhang et al., 2005). One of the drawbacks of using the MMT clay mineral as reinforcing filler for rubber is the incompatibility between hydrophilic clay and hydrophobic polymer, which often causes agglomeration of the clay within the polymer matrix. Therefore, surface modification of the clay is an important step to achieve rubber nanocomposites. The cations, which are placed within the clay gallery, can be exchanged with other inorganic or organic ions, for example quaternary alkyl ammonium ions (Yahaya et al., 2010). Organophilic modification makes the clay silicate layers compatible with the polymer. Such modified clays are commonly called as organoclay (OCs) (Zang et al., 2005).

In Rubber-clay nanocomposites, incorporation of a few weight percent of OC minerals that are properly dispersed throughout the polymer matrix, thus create much higher surface area for polymer/OC interaction as compared to conventional composites resulting in better reinforcement (Bhowmick et al., 2010). Reinforcement of rubber is associated with the enhancement of the modulus, failure properties (tensile and tear strength) etc, of the vulcanizates. However, to achieve nanoreinforcement, clay particles should be separated/delaminated into individual clay platelets which are $1 \mathrm{~nm}$ in 
thickness (Hakim and Ismail, 2009). Generally, reinforcement of the rubberclay nanocomposite predominantly depend on the cross linking chemistry of the rubbers, nature of the fillers, the physical and chemical interaction of the clay layers with the rubber matrix and, especially, on the degree of clay exfoliation/dispersion within the rubber matrix (Amarasiri et al., 2013). Hence, optimizing curing characteristics, especially processing safety and curing efficiency, degree of filler dispersion and filler-matrix interaction is vital to achieve the desired processability and physio-mechanical properties of any filled rubber compounds.

The objective of this research study was to investigate the effect of organoclay, especially organic modifier on curing characteristics and reinforcement of the NR compounds. Curing properties and reinforcement of organoclay filled NR compounds are also compared against the pristine MMT clay.

\section{Materials and Methods \\ Materials}

NR in the form of ribbed smoked sheet (RSS) with a Mooney viscosity of 95 (ML $\left.(1+4) 100^{\circ} \mathrm{C}\right)$ was purchased from Shums Rubber and Company Ltd. Sodium montmorillonite clay $\left(\mathrm{Na}^{+}-\right.$ MMT) with a cation exchange capacity of 95 meq of clay and organically modified montmorillonite clay (Closite
20A) supplied by Southern Clay Products, Inc. Co. Ltd. were used as clay mineral. Closite $20 \mathrm{~A}$ is a surfacemodified with dimethyl dihydrogenated tallow, quaternary ammonium modifier. The mean dry particle size of the organoclay is 6-13 $\mu \mathrm{m}$. All other rubber compounding ingredients used were of commercial grade.

\section{Preparation of natural rubber/clay nanocomposites}

Natural rubber/organoclay nanocomposites (NROCN) were prepared by melt compounding of NR with organoclay in the presence of other compounding chemicals in a laboratory scale internal mixer, model Haake PolyLab OS - Rheomix 600, operating at on-set temperature of $60{ }^{\circ} \mathrm{C}$ and with a rotor speed of $80 \mathrm{rpm}$ for 12 minutes. In addition, NR/clay composites (NRCC) were also prepared with equivalent unmodified montmorillonite clay loading similar to organoclay using the same internal mixer at similar processing parameters to evaluate the reinforcing and curing effect of organoclay in comparison to unmodified clay. The organoclay/ unmodified clay filled NR compounds were conditioned at $23 \pm 2{ }^{\circ} \mathrm{C}$ for $24 \mathrm{~h}$ prior to cure assessment. Table 1 presents the exact compound formulation for each NROCN and NRCC. 
Natural rubber/clay nanocomposites

Table 1. Compound formulations for NROCN and NRCC

\begin{tabular}{lcc}
\hline Ingredients & NRCC (phr) & NROCN (phr) \\
\hline Natural rubber & 100 & 100 \\
MMT & $2-10$ & - \\
OMMT & - & $2-10$ \\
Zinc oxide & 5 & 5 \\
Stearic acid & 2 & 2 \\
IPPD $^{\mathrm{a}}$ & 1 & 1 \\
Sulphur & 2.5 & 2.5 \\
TBBS $^{\mathrm{b}}$ & 1.2 & 1.2 \\
CTP $^{\mathrm{c}}$ & 0.4 & 0.4 \\
\hline
\end{tabular}

${ }^{\mathrm{a}} \mathrm{N}$-Isopropyl- N'-phenyl-P-phenylenediamine, ${ }^{b} \mathrm{~N}$-t-butylbenzothiozole-2-sulphanamide,

${ }^{\mathrm{c}} \mathrm{N}$-(cyclohexylthio) pthalimide

\begin{abstract}
Analysis of cure characteristics
The cure characteristics of organoclay/unmodified clay filled NR compounds were studied using a Moving Die Rheometer (EKTRON$2000 \mathrm{~S})$ at $150{ }^{\circ} \mathrm{C}$. Cure characteristics of each compound such as cure time $\left(\mathrm{T}_{90}\right)$, scorch time $\left(\mathrm{Ts}_{2}\right)$, cure rate index (CRI) and maximum torque were derived from the rheographs. Compounds were then compression moulded at $150{ }^{\circ} \mathrm{C}$ for the respective cure times derived from rheographs.
\end{abstract}

\section{Characterization NR nanocomposite structures}

Both NROCN and NRCC vulcanizate sheets prepared with compression moulding were analysed with X-ray diffraction technique to evaluate the intercalation and exfoliation behaviour of clay and to determine the interlayer spacing of clay within the nanocomposite materials. X-ray diffraction (XRD) analysis of the nanocomposites was performed with a Bruker D8 diffractometer at a wave length of $1.54 \AA$ of $\mathrm{Cu} \mathrm{K \alpha}$ radiations, by scanning over Brag angle $(2 \theta)$ range from $1-10^{\circ}$ at a scanning rate of $1 \% \mathrm{~min}$. The conventional Bragg equation $(n \lambda=$ $2 d \sin \theta$ ) was used to calculate the interlayer spacing of the clay in the nanocomposite materials. $\lambda$ is the wave length of X-rays, $d$ is the crystal lattice spacing, $\theta$ is the angle between incident radiation and the scattering plane, and $\mathrm{n}$ is the order of reflection.

\section{Reinforcing effect of organoclay}

Solid state mechanical properties of NROCN vulcanisates were analysed in comparison to NRCC vulcanisates and NR-gum vulcanisates containing no clay to study the reinforcing effect of organoclay. Tensile and tear properties of the NR vulcanisates were performed at a cross-head speed of $500 \mathrm{mmmin}-{ }^{1}$ using INSTRON, model 3365 Universal Testing Machine according to ISO 37 
(2005) and ISO 34 (2010) standard methods respectively. Hardness (IRHD) and compression set were measured according to ISO 7619 (2010) and ISO $815-1(2008)$ respectively.

\section{Analysis of tensile fracture surface}

Tensile fracture surfaces of organoclay filled NR nanocomposites and unmodified clay filled NR composites were observed under scanning electron microscope (SEM) to understand the tensile fracture behaviour of NROCN. SEM analysis of the clay filled NR vulcanizates was carried out with an electron microscope, model HITACHI SU6600 (SEM) at high vacuum mode operated at $30 \mathrm{kV}$. The fracture surfaces of the specimens were mounted on aluminium stubs and sputter coated with a thin layer of gold to avoid electrostatic charging during examination.

\section{Results and Discussion \\ Vulcanization characteristics of organoclay/clay filled rubber compounds}

Curing characteristics of the clay filled NR compounds measured with the moving die rheometer are presented in Table 2 whilst Figures 1 and 2 show the effect of organoclay/clay on scorch time, $\mathrm{TS}_{2}$ and cure time, $\mathrm{T}_{90}$ for both NROCN and NRCC compounds respectively.

As shown in Figures 1 and 2, NR-gum compound (containing no clay) cured with a conventional vulcanization system exhibited a good processing safety; a scorch time of $473 \mathrm{~s}$ and optimum cure of 1008 s. However, addition of organoclay into the NR showed a significant reduction in on-set vulcanization time (scorch time) and, as a result reduced processing safety and curing time of the compound. For example, scorch time of NROCN compound containing $2 \mathrm{phr}$ of $\mathrm{OC}$ is reduced from $473 \mathrm{~s}$ to $135 \mathrm{~s}$ whilst optimum cure time is compressed from $1008 \mathrm{~s}$ to $426 \mathrm{~s}$. These curing data indicates that organoclay behaves as an effective accelerating agent for NR vulcanization reaction. This could be attributed to the fact that organic modifier, dimethyl dihydrogenated tallow quaternary ammonium, in the organoclay acts as an accelerating agent by reducing the activation energy of the sulphur vulcanization reaction, resulting in reduced on-set vulcanization time. It has been reported (Galimberti, 2011; Jacob et al., 2007; Ishiaku et al., 1998; Akiba and Hashim, 1997) that amine groups facilitate the curing reaction of NR compounds.

In contrast to NROCN compounds, NRCC compounds do not show a significant variation of scorch time and optimum cure time in comparison to NR-gum compound, further confirming the effect of organic modifier on vulcanization reaction. 
$\square$ DRCCs $\quad$ QNROCNs

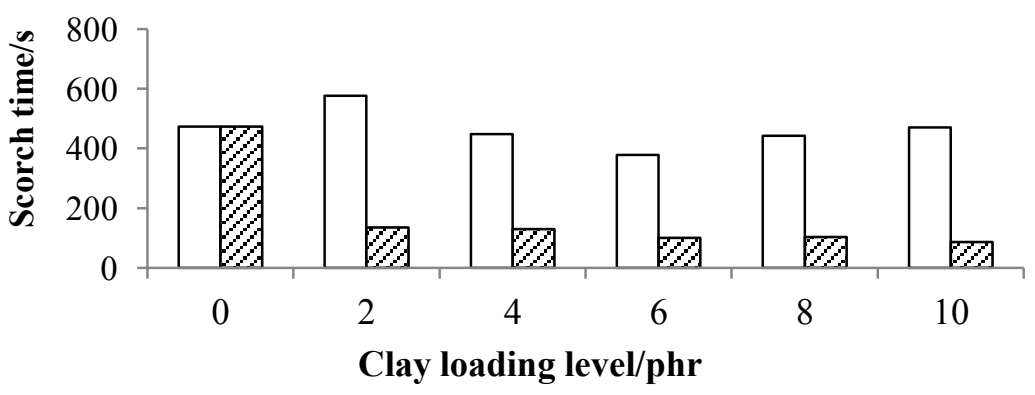

Fig. 1. The effect of clay loading on scorch time of NRCCs and NROCNs

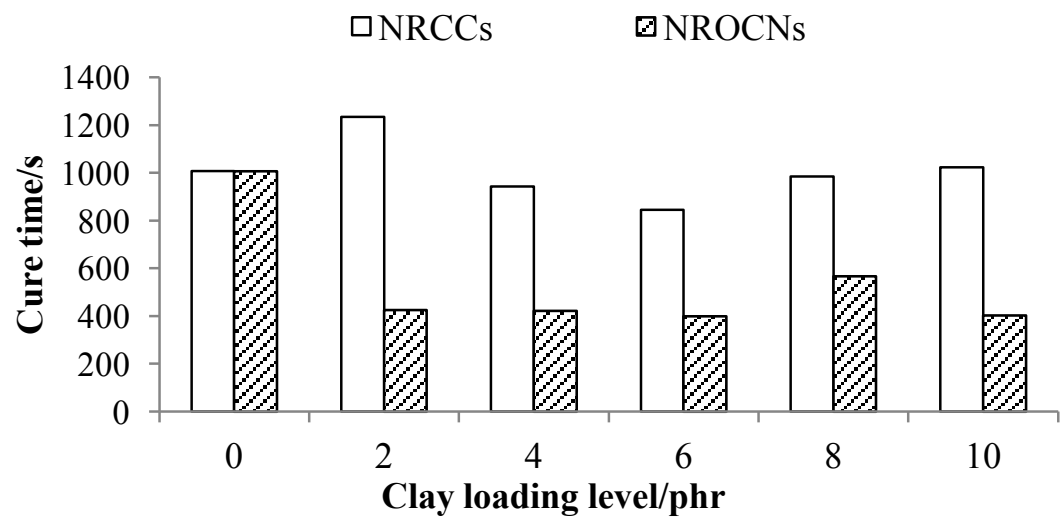

Fig. 2. The effect of clay loading on cure time of NRCCs and NROCNs

Table 2. Curing characteristics of NRCCs and NROCNS

\begin{tabular}{ccccccc}
\hline \multirow{2}{*}{$\begin{array}{c}\text { Clay loading } \\
\text { (phr) }\end{array}$} & \multicolumn{2}{c}{$\mathbf{C R I} / \mathbf{s}^{-1}$} & \multicolumn{2}{c}{$\mathbf{M H} / \mathbf{d N m}$} & \multicolumn{2}{c}{$\Delta \mathbf{M} / \mathbf{d N m}$} \\
\cline { 2 - 7 } & NRCC & NROCN & NRCC & NROCN & NRCC & NROCN \\
\hline $\mathbf{0}$ & 0.19 & 0.19 & 13.93 & 13.93 & 12.47 & 12.47 \\
$\mathbf{2}$ & 0.15 & 0.34 & 14.81 & 17.45 & 13.58 & 15.68 \\
$\mathbf{4}$ & 0.20 & 0.34 & 14.36 & 18.15 & 12.93 & 16.43 \\
$\mathbf{6}$ & 0.21 & 0.33 & 14.55 & 19.05 & 12.89 & 17.57 \\
$\mathbf{8}$ & 0.18 & 0.22 & 14.29 & 18.40 & 12.47 & 17.08 \\
$\mathbf{1 0}$ & 0.18 & 0.32 & 14.49 & 18.57 & 12.94 & 16.88 \\
\hline
\end{tabular}


Table 2 shows the cure rate index, maximum torque, $\mathrm{MH}$, and delta torque $(\Delta \mathrm{M}$, torque difference between maximum torque and minimum torque) for both NRCCs and NROCNC compounds. It can be seen that with an increase of organoclay loading $\Delta \mathrm{M}$ increased gradually to a maximum level at $6 \mathrm{phr}$ beyond that no significant change whereas there is no significant change in $\triangle \mathrm{M}$ of NRCC compounds. In general, $\Delta \mathrm{M}$ of a NR compound is an indication of the crosslink density of the compound and the reinforcement achieved with filler. These results clearly suggest that NROCN compounds have higher crosslink density than that of NRCC compounds, and as a result likely to have a higher reinforcing effect of organoclay.

\section{Characterization of NR-clay nanocomposite materials}

Figures 3 and 4 represent the X-ray diffractograms for unmodified clay (MMT) filled and organoclay (OC) filled vulcanizates, respectively. The characteristic diffraction peak $\left(d_{001}\right)$ of pure MMT clay is appeared at Bragg angle of $7.33^{\circ}$ (Fig. 3), resulting in interlayer spacing of $11.8 \AA$. As shown in Figure 3, when NRCC is prepared by incorporating MMT clay, diffraction peaks $\left(d_{001}\right)$ of NRCC's are slightly shifted towards lower Bragg angles. This could be due to the diffusion of low molecular weight substances used in compounding process into the clay inter gallery space. Based on the X-ray diffraction data of NRCC, it is clear evident that NR molecules do not intercalate into the MMT clay gallery and as a result phase separated conventional microcomposites are formed.

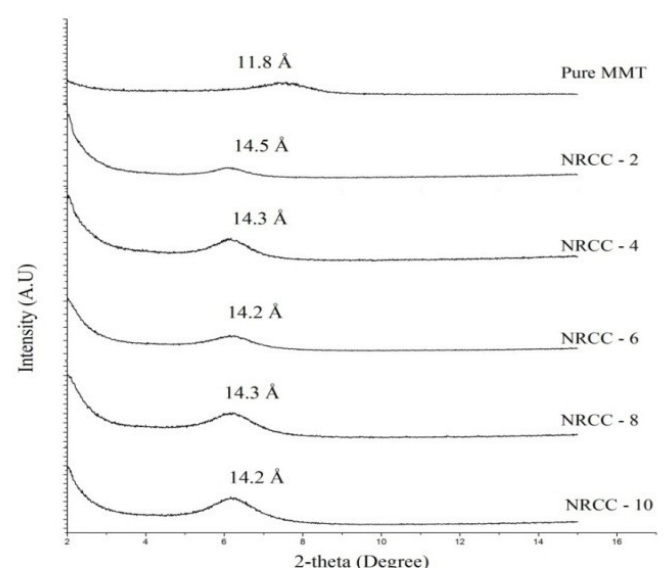

Fig. 3. X-ray diffractograms for NRCCs prepared with different loading of unmodified (MMT) clay 


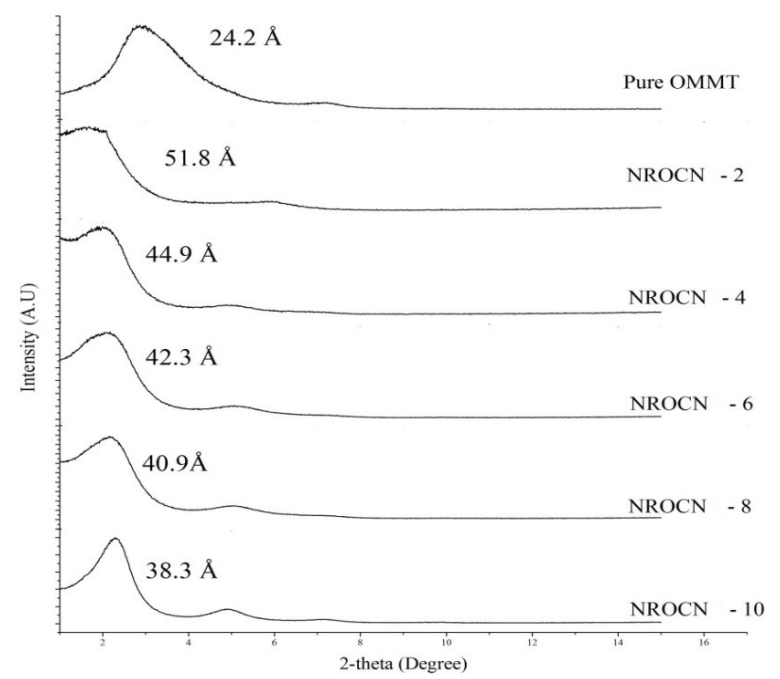

Fig. 4. X-ray diffraction spectra for NROCNs prepared with different loading of organoclay

As shown in Figure 4, pure OMMT clay shows the diffraction peak $\left(d_{001}\right)$ at Bragg angle of $2.84^{\circ}$ which is assigned to the interlayer spacing of $24.2 \AA$. When NROCNs were prepared with $\mathrm{OC}$, as presented in Figure 4, the $d_{001} \mathrm{X}$ ray diffraction peak of $\mathrm{OC}$ in all nanocomposites shows a much more significant shifting towards a lower Bragg angle, resulting in significant increase in the interlayer spacing than pure OC. The significant increase in OC clay gallery space in the NROCNs can be explained referring to the hypothesis that NR molecules along with low molecular weight substances intercalate into the clay gallery during the compounding process resulting in an expansion in the gallery region due to the compatibility between the two entities. For example, as result of this intercalation of NR molecules, the diffraction peak of $2 \mathrm{phr}$ OC filled NROCN shifted from $24.2 \AA$ (pure OC, as supplied) to $51.8 \AA$, with an increase of $27.6 \AA$. Higher interlayer spacing caused to weaken the Vander-Wall attractive forces between clay platelets and as a result, exfoliation of $\mathrm{OC}$ in the NROCNs is facilitated during the high shear melt mixing process in the internal mixer. Hence, $\mathrm{OC}$ in the NROCNs exfoliates into either single platelets or smaller stacks with a few clay platelets, resulting in intercalated/exfoliated nanocomposite structure. However, as shown in Figure 4 , with the increase of OC loading from 2 to $10 \mathrm{phr}$, X-ray diffraction peak becomes gradually narrow and shifted slightly towards a higher diffraction angle. This implies that higher clay loading affects to the degree of exfoliation and resulting thicker clay 
stacks containing comparatively higher number of clay platelets.

\section{Mechanical properties of NROCN vulcanizate materials}

The effect of organoclay on reinforcement of NROCN vulcanizate materials were evaluated in comparison to NR-gum vulcanizate and NRCC vulcanizates containing equivalent clay loading similar to NROCNs vulcanizates.

Figure 5 shows the tensile stress-strain curves for NROCNs vulcanizates with increasing loading levels of organoclay while Figures 6 and 7 show the tensile strength and tear strength of both NROCN and NRCC vulcanizates. Stress-strain properties such as tensile strength and tear strength have clearly shown that modified clay significantly enhanced the reinforcement of NROCN vulcanizates compared to that of NR- gum and NRCC vulcanizates. This can be explained referring to the argument that the organoclay is more compatible with NR matrix than unmodified MMT and as a result NR molecules diffuse into the organoclay gallery, leading to a better exfoliation/dispersion of organoclay in the NR matrix. As a result, organoclay particles are separated into either individual clay platelets with $1 \mathrm{~nm}$ thickness or smaller stacks with a few clay platelets as confirmed by X-ray diffraction results (Fig. 4). Improved dispersion/ exfoliation of organoclay within the rubber matrix would lead to increase the aspect ratio as well as the specific surface area of organoclay. Higher surface area is caused to improve interfacial interaction between organoclay and NR molecules resulting in good strength characteristics of NROCNs vulcanizates.

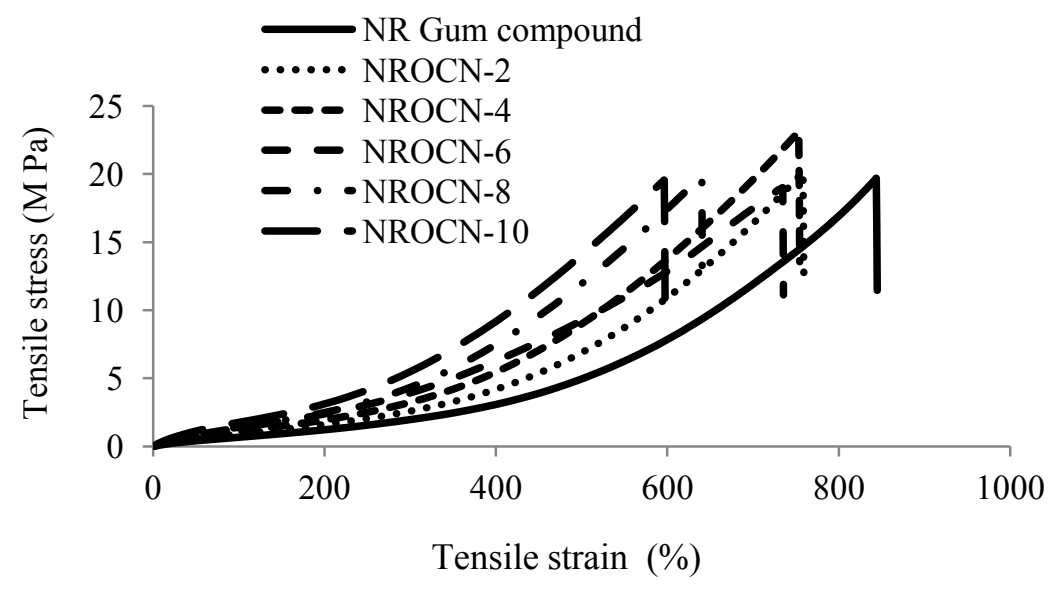

Fig. 5. Stress-strain curves of NROCNs vulcanizates 


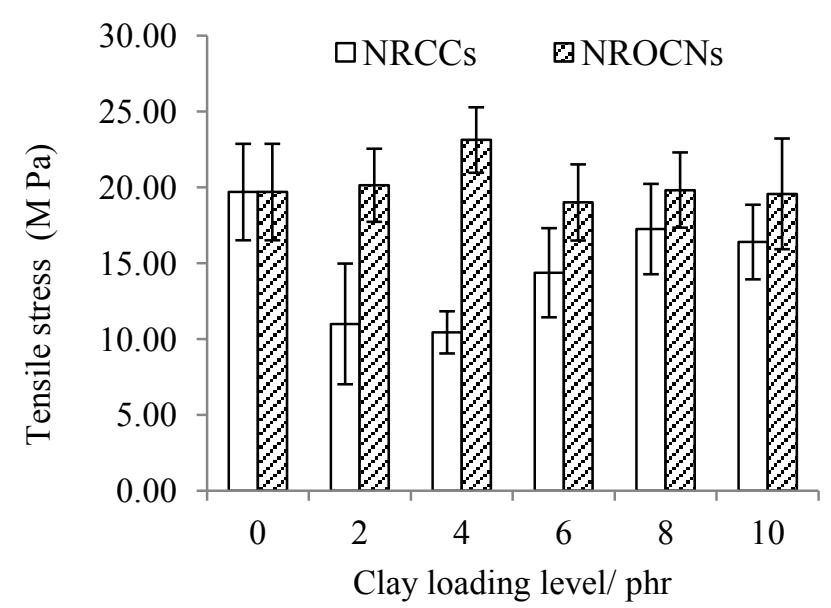

Fig. 6. Effect of clay loading on tensile strength of NRCCs and NROCNs

On the other hand, addition of unmodified MMT clay into NR reduce both tensile strength and tear strength, suggesting that MMT clay does not exfoliate during the compounding process due to the incompatibility with NR and resulting in agglomerated larger clay stacks in the NRCC vuclanizates. Those larger clay particles act as nonreinforcing filler and therefore reduce the strength characteristics.

A significant improvement (about 40\%) of tear strength was observed in NROCN in comparison to NR-gum and NRCC (Fig. 7). In NROCN, higher degree of exfoliation and enhanced compatibility, as a result of organic modification, with the NR matrix would result more interaction with the matrix. The stress generated at the interface between NR and organoclay is effectively transferred to the bulk NR and hence resistance to crack initiation is improved in NROCN in comparison to NRCC. But in the case of NRCC, unmodified MMT clay dispersed in the matrix as stacks with micrometer thickness. These larger clay stacks have poor interaction with the NR matrix, leading to create stress concentrating points and as a result crack initiation start at a lower force, leading to poor tear strength in NRCC.

According to Figures 6 and 7, tensile and tear strength show a maximum value at $6 \mathrm{phr}$ of organoclay loading, beyond above it reduces. At higher OC loading, degree of exfoliation is reduced, as shown in X-ray diffraction spectra in Figure 4, and therefore more intercalated clay morphology (i.e. larger clay stacks) within the nanocomposite material, resulting in overall reduced strength characteristics. 


\section{$\square \mathrm{NRCCs} \quad \square \mathrm{NROCNs}$}

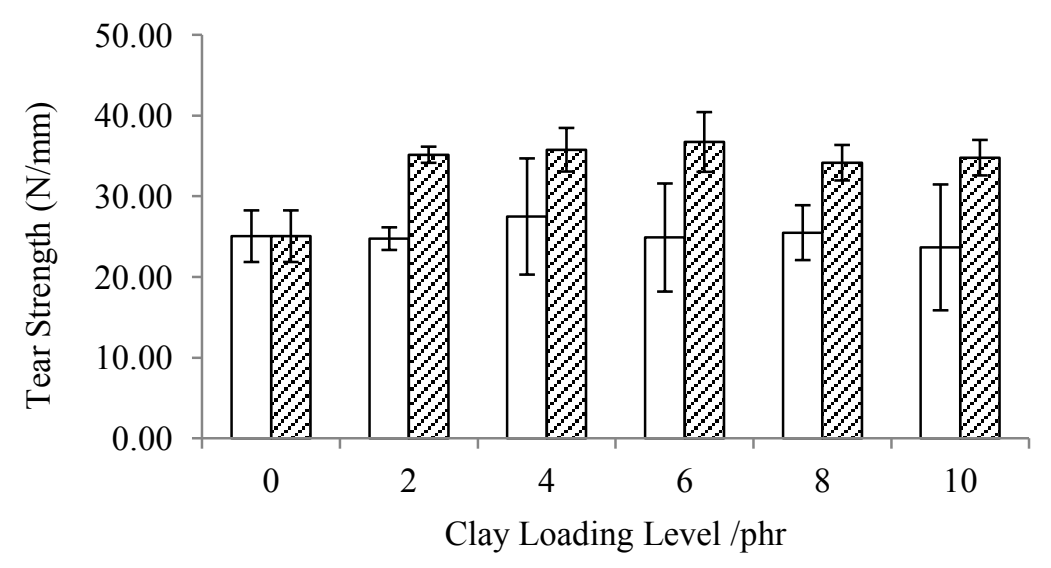

Fig. 7. Effect of clay loading on tear strength of NRCCs and NROCN
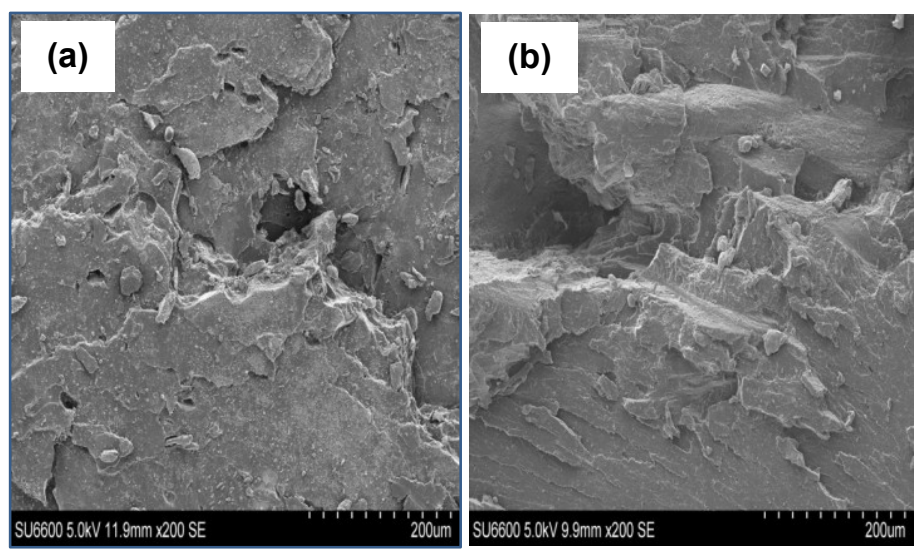

Fig. 8. SEM micrographs showing tensile fracture surface of (a). NRCC-6 (b). NROCN-6

Figure 8 (a) and (b) shows the SEM micrograph of tensile fracture surfaces of NRCCs and NROCN with $6 \mathrm{phr}$ filler loading respectively. A significant decrease in voids and cavities in NROCN was observed compared to that of NRCC. Based on these results, it can be suggested that the rougher the fracture surface with many curved tearing with minimal voids or cavities, the better the failure properties of the nanocomposites. Arroy et al. reported that smooth fracture surface usually indicates low compatibility accompanied with premature and rather brittle-type fracture (Arroy et al., 2005). 
Modulus at $300 \%$ elongation at break, hardness and compression set of the studied rubber compounds are compiled in Table 3. Low reinforcing effect of un-modified MMT clay was evident with the mechanical properties of NRCC vulcanizates as shown in Table 3. A poor exfoliation and dispersion of un-modified MMT clay within NR matrix, because of limited compatibility, was expected and, but, a marked increase in mechanical properties was observed with the organoclay, as filler.

As shown in Table 3, improvement in hardness of NROCN vulcanizates further confirmed the significant reinforcing ability of OC in NR compounds. Addition of $6 \mathrm{phr}$ organoclay into NR (NROCN-6) increased by about $43 \%$ in comparison to NR-gum vulcanizate whereas no significant change in hardness with the addition of un-modified MMT clay. Improved hardness is achieved with a lower loading of OC because of the exfoliation of clay particles and subsequent uniform dispersion of clay platelets/smaller stacks within the NR matrix. In addition, higher crosslink density achieved due to $\mathrm{OC}$ is further contributed to improve the hardness. In contrast, lower hardness value for NRCCs vulcanizates clearly confirm the formation of conventional phase separated microscale composite, with a poor rubber-filler interactions.

Table 3. Mechanical properties of NROCN and NRCC vulcanizate

\begin{tabular}{|c|c|c|c|c|c|}
\hline ن & 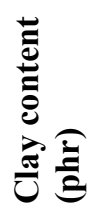 & 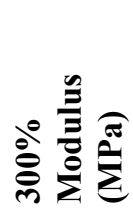 & 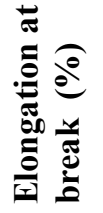 & 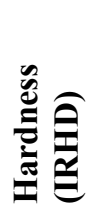 & 章 \\
\hline \multirow{6}{*}{$\begin{array}{l}U \\
\frac{\mathscr{z}}{Z}\end{array}$} & 0 & 1.97 & 844 & 33.7 & 6.49 \\
\hline & 2 & 1.45 & 791 & 29.7 & 5.91 \\
\hline & 4 & 1.49 & 780 & 30.5 & 6.85 \\
\hline & 6 & 2.08 & 755 & 30.9 & 5.45 \\
\hline & 8 & 2.51 & 745 & 31.5 & 5.78 \\
\hline & 10 & 2.45 & 745 & 30.8 & 6.37 \\
\hline \multirow{6}{*}{$\begin{array}{l}U \\
Z \\
0 \\
0 \\
z \\
z\end{array}$} & 0 & 1.97 & 844 & 33.7 & 6.49 \\
\hline & 2 & 2.59 & 758 & 44.9 & 6.77 \\
\hline & 4 & 3.24 & 754 & 45.1 & 8.77 \\
\hline & 6 & 3.93 & 735 & 48.2 & 12.21 \\
\hline & 8 & 4.34 & 641 & 48.0 & 12.61 \\
\hline & 10 & 5.50 & 596 & 49.2 & 13.66 \\
\hline
\end{tabular}


More importantly, elasticity as measured with elongation at break, of NROCNs, especially with an OC loading less than $6 \mathrm{phr}$, was not sacrificed while improving the stiffness and strength of the NROCNs. As clearly illustrated in Table 3, elongation at break of $6 \mathrm{phr}$ of OC filled NROCN is reduced from $844 \%$ (EB of NR-gum vulcanizate) to $735 \%$, demonstrating a marginal reduction of elasticity of NROCNs with respect to NR-gum vulcanizate. However, on the other hand, without reinforcing, equivalent reduction of elasticity in NRCC prepared with unmodified MMT clay was observed, further indicating the significant advantage of using $\mathrm{OC}$ as a reinforcing material for NR compounds. It is important to note that the elastic characteristic, as deduced from the compression set measurements, of NR matrix hardly varies with the addition of the organoclay (Table 3), especially up to the addition of $6 \mathrm{phr}$ of organoclay. These results clearly indicate that elasticity of NROCN vulcanizates was marginally affected with the addition of $\mathrm{OC}$, especially with lower loadings.

\section{Conclusion}

The effect of organoclay on curing characteristics and reinforcing effect of NR compounds were studied in comparison to equivalent un-modified MMT clay filled NR compounds.

Rheological studies in terms of vulcanization kinetics have shown that organoclay reduces the activation energy of the sulphur vulcanization reaction and as a result significant reduction of processing safety as measured by on-set vulcanization time of the NROCN compounds. Enhanced crosslink density of the NROCN's indicated the improved compatibility between OC and the NR matrix.

X-ray diffraction data revealed that intercalated/exfoliated nanoclay structure is formed when $\mathrm{OC}$ is melt compounded with NR, especially with lower OC loading. However, with the increase of OC loading, intercalated OC structure with a higher number of clay platelets becomes dominant, leading to reduced degree of exfoliation. On the other hand, un-modified MMT clay has not shown any intercalation/exfoliation process during melt compounding process, resulting in phase separated conventional micro-composite.

A significant increase in tensile properties and hardness of the NROCN's vulcanizates relative to NRgum and NRCC vulcanizates confirms the significant reinforcement effect of OC against un-modified MMT clay in NR compound formulations. In addition, stiffness and strength of the NROCN's vulcanizates were improved while maintaining a good elasticity, as measured by elongation at break and compression set, similar to the NR-gum vulcanizate.

\section{Acknowledgements}

Authors wish to acknowledge National Research Council (NRC) of Sri Lanka 
for the financial support provided through a research grant to carry out this research project. Other contributions, especially Sri Lanka Institute of Nanotechnology (SLINTEC) for providing characterization facilities for the nanocomposite samples are also acknowledged with thanks.

\section{References}

Akiba, M and Hashim, A S (1997). Vulcanization and crosslinking in elastomers. Progress in Polymer Science 22, 475-521.

Amarasiri, A, Ratnayake, U N, De Silva, U $\mathrm{K}$, Walpalage, $\mathrm{S}$ and Siriwardene, $\mathrm{S}$ (2013). Natural rubber latex-clay nanocomposite: use of montmorillonite clay as an alternative for conventional $\mathrm{CaCO}_{3}$. Journal of National Science Foundation 41, 293-302.

Arroyo, M, Lopez-Manchado, M A, Valentin, J L and Carretero, J (2007). Morphology/behaviour relationship of nanocomposites based on natural rubber/epoxidized natural rubber blends. Composites Science and Technology 67, 1330-1339.

Bhowmick, A K, Bhattacharya, $\mathrm{M}$ and Mitra, S (2010). Exfoliation of nanolayer assemblies for improved natural rubber properties: Methods and theory. Journal of Elastomers and Plastics 42, 517-536.

Chonkaew, Wunpen, Withawat Minghvanish, Ulchulee Kungliean, Nutthaya Rochanawipart and Witold Brostow (2011). Vulcanization characteristics and dyanamic mechanical behaviour of natural rubber reinforced with silane modified silica. Journal of Nano Science and Technology 11, 20182024.
Ehabe, E E and Farid, S A (2001). Chemical kinetics of vulcanisation and compression set. European Polymer Journal 37, 329-334.

Galimberti, M (2011). Rubber-clay nanocomposites, science, technology and applications, Hoboken, New Jersey, John Wiley \& Sons, Inc.

Hakim, R N and Ismail, H (2009). Comparison of the effects of organoclay loading on the curing and mechanical properties of organoclay-filled Epoxidised Natural Rubber nanocomposites and organoclay-filled natural rubber nanocomposites. Journal of Physical Science 20, 37-59.

Jacob, A, Kurian, P and Aprem, A S (2007). Cure characteristics and mechanical properties of natural rubber-layered clay nanocomposites. International Journal of Polymeric Materials 56, 593-604.

Jia, Qing-Xiu, Wu, You-Ping, Wang, YiQing, Lu, Ming and Li-Qun Zhang (2008). Enhanced interfacial interaction of rubber/clay nanocomposites by novel two-step method. Composites Science and Technology 68, 1050-1056.

Murakami, K, Iios, S, Tanahashi, T, Kohjiya, S, Kajiwara, K and Ikeda, Y (2001). Reinforcement of NR by silica generated in situ: comparison with carbon black stock. Kautschuk Gummi Kunststoffe 54, 668-672.

Poh, B T and Ng, C C (1998). Effect of silane coupling agents on the mooney scorch time of silica-filled natural rubber compound. European Polymer Journal 34, 975-979.

Qureshi, M N and Qammar, H (2010). Mill processing and properties of rubber-clay nanocomposites. Material Science and Engineering 30, 590-596.

Ratnayake, U N and Haworth, B (2006). Polypropylene-clay nanocomposites: 
influence of low molecular weight polar additives on intercalation and exfoliation behavior. Polymer Engineering and Science 46, 1008-1015.

Ratnayake, U N, Haworth, B and Hourston, D J (2008). Preparation of polypropylene-clay nanocomposites by the cointercalation of modified polypropylene and short-chain amide molecules. Journal of Applied Polymer Science 112, 320-334.

Sadequl, A M, Ishiaku, U S, Ismail, $\mathrm{H}$ and Poh, B T (1998). The effect of accelerator/Sulphur ratio on the scorch time of epoxidized natural rubber. European Polymer Journal 34, 51-57.

Yahaya1, L E, Adebowale, K O, Menon, A R R, Rugmini, S, Olu-Owolabi, B I and Chameswary, J (2010). Natural rubber/organoclay nanocomposites: Effect of filler dosage on the physicomechanical properties of vulcanizates. African Journal of Pure and Applied Chemistry 4, 198-205.
You-Ping $\mathrm{Wu}$, Yi-Qing Wang, Hui-Feng Zhang, Yi-Zhong Wang, Ding-Sheng Yu, Li-Qun Zhang and Jun Yang (2005). Rubber-pristine clay nanocomposites prepared by co-coagulating rubber latex and clay aqueous suspension. Composites Science and Technology $\mathbf{6 5}$, 1195-1202.

Zeng, Q H, Yu, A B, Lu, G Q (Max) and Paul, D R (2005). Clay-based polymer nanocomposites: research and commercial development. Journal of Nanoscience and Nanotechnology 5, 1574-1592.

Address for correspondence: Dr Upul Ratnayake, Senior Research Officer, Raw Rubber Process Development \& Chemical Engineering Dept., Rubber Research Institute of Sri Lanka, Telewela Road, Ratmalana, Sri Lanka.

e-mail:un_ratnayake@yahoo.co.uk 